\title{
Cracked reinforced concrete walls of chimneys, silos and cooling towers as result of using formworks
}

\author{
Marek $\mathrm{Maj}^{1}$, and Andrzej $\mathrm{Ubysz}^{1, *}$ \\ ${ }^{1}$ Chair of Civil Engineering, Faculty of Civil Engineering, 50370 Wrocław,Wyspiańskiego 27, Poland
}

\begin{abstract}
There are presented in this paper some problems connected with reinforced concrete shell objects operation in the aggressive environment and built in method of formworks. Reinforced concrete chimneys, cooling towers, silos and other shells were built for decades. Durability of cracked shells are one of the most important parameters during process of designing, construction and exploitation of shells. Some reasons of appearance of horizontal and vertical cracks as temperature, pressure of stored material, live loads e.g. dynamic character of wind, moisture, influence of construction joints, thermal insulation, chemistry active environmental etc. reduce the carrying capacity of the walls. Formworks, as is occurred recently, are the reason for technological joints with leaking connection, imperfections of flexible formworks slabs and as result can initiate cracks. Cracked surface of this constructions causes decreasing capacity and lower the state of reliability. Horizontal, vertical cracks can caused corrosion of concrete and steel bars, decreasing stiffness of contraction, increasing of deflection and carbonation of concrete cover. Local and global imperfactions of concrete shells are increasing according to greater number of cracks...
\end{abstract}

\section{Introduction}

In recent years many engineers objects are renovated. In particular industry objects are not only renovated but also strengthened. Most of them lost their designed durability life. The basic reason of it is carbonation of concrete, reinforcement corrosion, loss of concrete cover, too many cracks with wide-width, too large deformations and deflections, etc. Recently, more and more often investigates the impact of object on the environment. Mechanical vibrations caused by long-term or short-term operation of equipment in their immediate vicinity may also play a role. Interesting examples of monitoring such dynamic effects on chimneys are shown in $[1,2]$. But also due to the increasing standard requirements do not meet the requirements for reliable use. Another reason for renovated is change of kind of use of buildings i.e. change of live loads, change of constructions static schemas. During designing of this objects there is not expected regeneration or renovation

\footnotetext{
* Corresponding author: marek.maj@pwr.edu.pl
} 
of parts or of the whole object. Reduced resistance due to many years of buildings exploitation is included in partial safety coefficient because of fact that phenomenon of durability is stochastic process. But due to over-exploitation and unfavorable terms such as increased chemical activity on building, structures lose their reliability before the termination of operation of the facility

\section{Durability}

The basic equation of reliability of each of construction element and the whole construction can by described in following equation [3]

$$
\mathrm{A} \leq \mathrm{R}
$$

where $\mathrm{R}$ - construction resistance, A - loadings acting on construction. This equation is used by engineers in stresses quantities, or resultant forces. Forces are compressive or tensile or bending moments. Generally in Limit State Design (LSD) R is regarded as a strength and A as stresses. In Serviceability Limit State (SLS) R is allowable deflection or a allowable scratch and $\mathrm{A}$ is static deflection or calculated scratch. $\mathrm{R}$ is not simply limits stresses and A is not simply loads of snow, winter, pressure etc. Equation (1) has not simple, i.e, the linear form. It involves many parameters appropriate for the loads and strength. Equation (1) can be written in the following formula

$$
\mathrm{R}-\mathrm{A} \geq 0 \text { or } \mathrm{f}(\mathrm{R}-\mathrm{A}) \geq 0
$$

where function $f(R-A)$ we can define function of safety or reliability by: $R$ and A are treated as independent random value, but very often they are depended, particularly when loads are dynamic. Reduction of durability of construction material can began process of acceleration object destruction. According to [4], the durability of the material we mean its ability to maintain declared by the manufacturer the mechanical, functional and aesthetic material properties during design lifetime of the object. Durability of construction materials depends on the operation time of the facility, the stress number of cycles $\mathrm{N}$ of structures subjected to cyclic interactions and the number of exceedances of the limit states. Lowering the durability of materials reduces the computational resistance parameters and narrows the area of reliability of the whole structure. Durability of construction not only depends on properties of construction materials i.e. resistance of construction but also of properties of live loads. Such properties of load parameters as frequency, coefficient of variation, the ratio of load maximum to minimum, which characterized dynamic loads affect the behavior of the constructional material. So in this point of view acting loads - and construction resistance are not independent random values. Technological joints caused by formworks reduce the durability of the construction when they create cracks, leaks, and reduce the stiffness of the shell. Remedial work of repaired objects should restore designed reliability level of construction. But in fact during repairing there is a new construction built. New materials used to reconstruction of silo and chimney concrete cover form new multilayer silo wall. Injected or stapled cracks form walls composed of many reinforced concrete elements interconnected by network of injection. Replacement of reinforced steel bars or adding of bars change this static equilibrium which was taken into consideration in the original design. In another words repaired construction is not the same construction but only similar. As such should be re-calculated in terms of strength using new parameters of strength materials, schema static and endurance of the whole construction, i.e. ULS and SLS. 


\section{Constructions which lost resistance before the time of the end of design life}

Some examples of such constructions presents in this paper are industrials reinforced concrete chimneys, silos and cooling towers [5]. These structures are very similar to each other. They are usually built as a shell structures, with a relatively large height and thin walls. Concrete as a material in both structures subjects to similar environmental conditions, loads, technology of object rising, destruction of the structure. In these two cases determines the safety of buildings, control of the same way. Both types of structures are similarly reinforced. They built by using formworks. The difference between them is in the prevalence of certain loads, in access to the individual elements of structure, in differentiated impact of aggressive chemicals.

\section{The causes of reduced durability of chimneys and cooling towers}

In designing chimney or cooling tower wall there are no place for the appearance of the larger cracks. Horizontal and vertical cracks can caused corrosion of concrete and steel bars. Cracks decreases stiffness of reinforced concrete chimney shell construction. Local and global imperfections of chimney walls are increasing according to greater number of cracks. Taking into account these facts, cracks reduce the service life of chimneys. Horizontal and vertical cracks allow condensate water infiltrates into wall. It causes corrosion and moisture of concrete wall and during winter time cracks become bigger because if glaciations water in cracks. Problems with a large number of cracks on chimneys or cooling towers walls occurred in last years in Poland. It was connected with e.g. changing chimney codes and in particularly introduction requirement of double reinforcement of concrete walls. Until the end of XX centaury reinforcement bars were located in one row, near the external surface. After receiving in Poland European Standards two rows of reinforcement are demanded. It caused several difficulties in building chimneys or cooling towers because of little space of reinforcement bars in rather thin wall. Additional problem of increasing number and widths of cracks is chimney insulation. Badly placed insulation results in an increase bending moments and the cracks are wider. Another problem is condensate which leaks through the joints and cracks. Increased temperature in the wall of the chimney insolation, chemical activity of condensate, damp thermal insulation, bad made joints causes increased corrosion of steel and concrete. The result of these are many defects of concrete cover. There are many mistakes which were made during building chimneys and cooling towers: too small distance between vertical and horizontal steel bars in concrete wall, insufficient concrete care during building, too rapid drying wall caused shrinkage in walls, using adjustable formwork in building chimneys, using joints in shell during building, non proper joint design, too long pause between subsequent concrete filling, using vibrators inappropriate for steel bars diameter and for distances between them, touching by vibrator steel bars, different distances between horizontal and vertical reinforced bars, differentials in strength of bars and in strength of concrete, different in concrete cover, diameter and area of bars of bars, imperfections in steel bars localization, height of compressed concrete area, quantity of reinforced horizontal and vertical bars, adhesion of bars to concrete, too small or destroyed thermal insulation, low quality of lap splices, type and quality of wall strengthening, imperfections, cracks, steel corrosion, technical condition of concrete, i.e. concrete carbonization, etc., destroyed moisture protecting coating, too much condensate inside chimney caused by low 
temperature of gas, too few steel bars calculated shrinkage for chimneys and cooling towers wall, adding loads on chimney of satellite dishes.

\section{The causes of reduced durability of silos}

There some reasons for reduced durability of silo walls. They arise from non-compliance of designed strength parameters. Mostly are errors of construction work, changes in operating external conditions as chemical aggression, changes of design assumptions. Specified above parameters are random variables, and during exploration of silo changed first of all coefficients of variation, i.e they increased. This resulted in a decrease of the characteristic values and computational strength parameters and increase the value of the characteristic loads. Additional parameters to those mentioned above are: This parameters are: temperature field on the silo wall caused by storage grain, insolation and daily temperature variation, temperature gradient across the silo wall, horizontal pressure caused by wind and grain pressure, concentrated loads (patch loadings), parameters connected with silo wall strength as changes in silo and thickness of the silo wall, changes in wall stiffness.

\section{Some examples of repairing of chimney and cooling tower}

On Fig. 1 are presented new chimney after one year of exploitation (height $180 \mathrm{~m}$, diameter $7,20 \mathrm{~m}$, wall thickness is $0,70 \mathrm{~m}$ in lower part). There are many cracks on the wall, cracked joints, destroyed concrete covers and condensate flowing from internal chimney space through cracks. Condensate formed inside the chimney flow through the cracks causes rust of steel and devastation of technological joints, which is shown on Fig. 2. Too long pause between subsequent concrete filling, using vibrators inappropriate for steel bars diameter and for distances between them and touching by vibrator steel bars caused destroyed area of joint. Cracks, separated steel bars from concrete wall changes monolithic wall to few interconnected pieces.

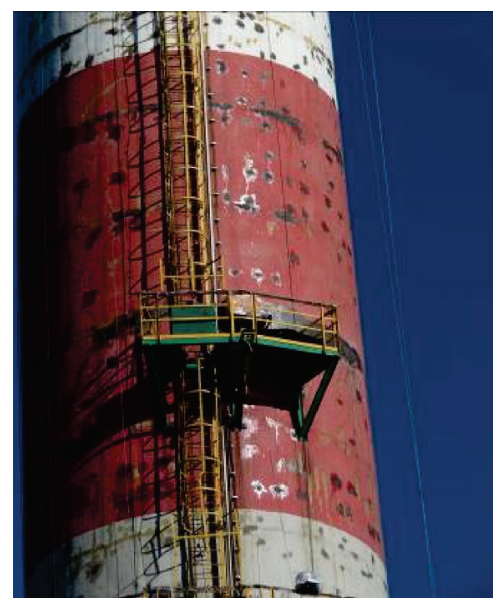

Fig. 1. New chimney after one year of exploitation with many cracks and condensate flowing from internal chimney space. Visible traces of replacement of concrete cover, injection of cracks, repair horizontal joints.

Thermal insulation protects chimney wall against high temperature and high temperature gradient resulting in an increase of the tension force and of the bending moment. 
Additional non uniform distribution of temperature on chimney wall causes increasing of deflection of chimney and increasing vertical inner forces. This is the reason that vertical and horizontal cracks appear additionally. Thermal insulation can be destroyed or may fall down because of excessive number of condensate penetrate to surface of chimney wall. Very similar factors as in the case of chimneys cause the destruction of concrete cover and reinforcement in cooling towers (Fig.3). Using similar methods as in the case of chimney cooling towers shown on Fig. 3 was repaired (Fig. 4).

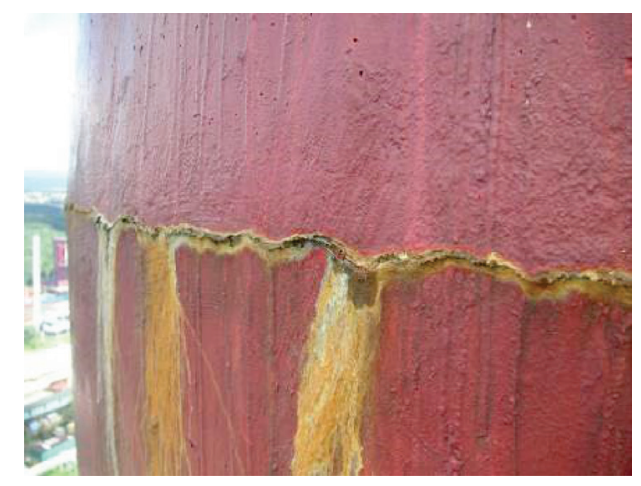

Fig. 2 The condensate flowing form horizontal cracked joints.

\section{Some examples of repairing of silos}

After many years of exploitation some silos construction need to be renovated and strengthened. Strengthening of silo construction (silo walls, bottom, foundations or overlap) can be carried out generally in two ways, according to formula (1) [3]. Decreasing of value of left side (loads) of this equation and increasing value of right side (strength) of this equation separately or simultaneously makes silo construction more safety. The first simplest solution used for silo is reducing the level of filling of the silo of material stored in silo or using perfect control of kinematic of discharging material and change the kinematic of flowing to chimney flow. It is possible using the discharging device decreasing value of material pressure. Second solution is increasing strength of the silo wall, using additional materials of higher strength as steel hoops, prestressed tendons (Fig. 5) [4].

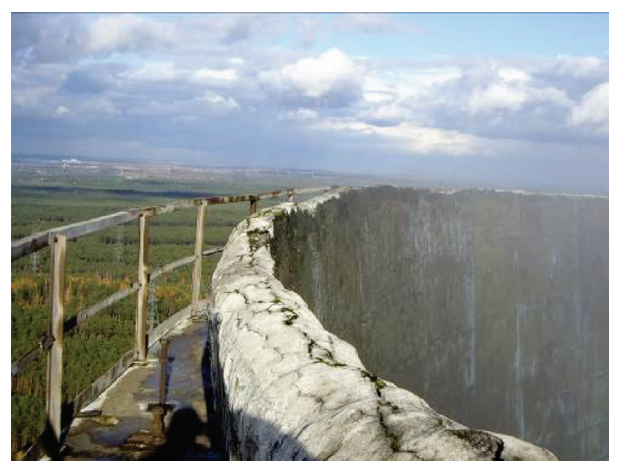

Fig. 3. Destroyed upper reinforced concrete crown. 
Typical concrete silos for rape built 40 years ago in many places in Poland were renovated and most of them were strengthened. On Fig. 6 it is shown the rechange of cover and corroded reinforcement.

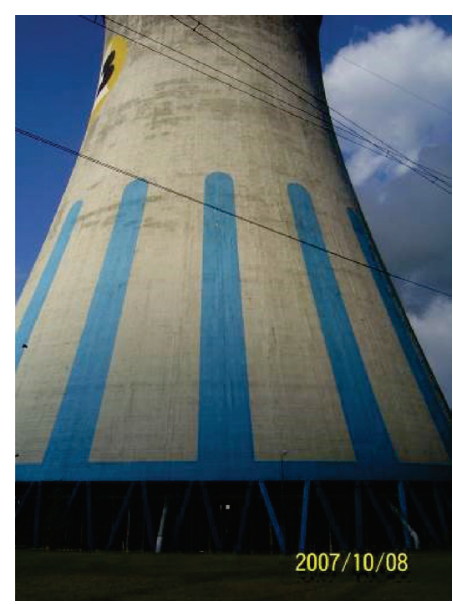

Fig. 4. Renovated cooling tower.

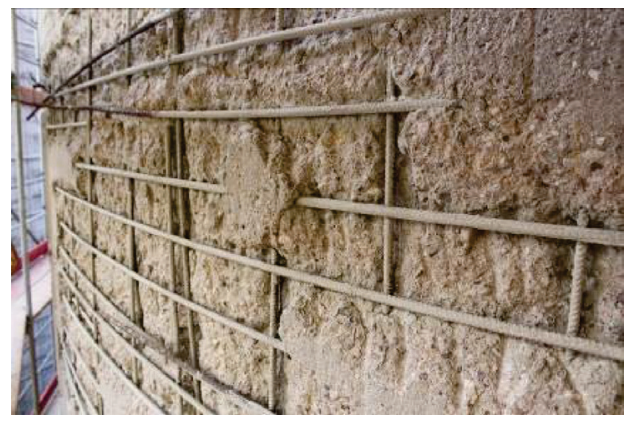

Fig. 5. Most of concrete cover and corroded steel bars are replaced.

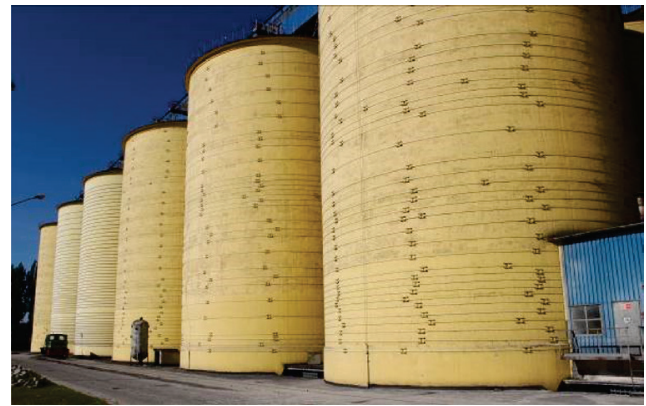

Fig. 6. Silo battery for rape partially strengthened by steel hoops and prestressed tendons.

\section{The methods used to restore the durability of reinforced concrete structures}

The typical methods used to restore the durability and strength of reinforced concrete silos, chimneys and cooling towers are: removing the shattered parts of carbonated concrete and 
outer coatings in joints and cracks in the wall, reprofiling walls and cleaning reinforcement steel bars and supplement missing bars, repair corroded reinforcement, replacement of damaged parts of the concrete wall filling cracks and joints by injection materials, location of additional reinforcement, hoops or prestressed, or carbon fiber tapes, location of the additional layers of concrete, restoration of the thermal insulation and moisture of the concrete wall (chimneys), additional calculations strength of the new repaired structure [5]

The strength calculations took into account the many layers renovated walls. So in this case new object was created. New concrete was used with another strength parameters as adhesion, plasticity, cohesion, moisture etc. The surface of the repaired structure is subjected to shear, delaminated stresses etc. The most important for new materials is fact that they were not rejected by the parent material. New parts of the structure are not as strained as those that already exist, don't undergone the process of rheology, introducing additional self stresses in the joint place between old and new material. These physical phenomena must be taken into account in the calculation of strength of new construction.

\section{Conclusions}

All designed constructions are subject to aging. You cannot design a structure where all elements at the same time lose reliability. All constructions are subject to periodic repairs in order to restore the designed resistance. However economic and technological aspect decides about the repair. It is very important to choose the method of formwork and it seems that the formwork requires a lot of attention. It seems that in the initial design of construction process should be included restoration of the durability of the object whole or part of it. During the initiate construction design process should be consider and indicate the places with maintaining the durability of materials. Such designed repairs should be considered in terms of the need strengthening, possibility of technology, economics, health of workers, the impact on the ecology of the environment, etc.Renovated structure is not the same as original designed object. Should be reconsidered basic static schemes and equations applied equations strength.

\section{References}

1. A. Herbut, J. Rybak, Guidelines and recom-mendations for vibration control in the case of rapid impulse compaction, Advances and trends in engineering sciences and technologies II, 761-766 (CRC Press, Taylor \& Francis Group, 2017)

2. J. Rybak, A.G. Tamrazyan, Calibration of rapid impulse compaction on the basis of vibration velocity control, 16th International Multidiscip. Scientific GeoConference SGEM 2016, Albena, Bulgaria, 30 June-6 July, 2016 vol. 1, 715-722, (2016)

3. H. O. Madsen, Methods of structural safety (Prenice Hall, 1986)

4. Murzewski J., Niezawodność konstrukcji inzynierskich (Arkady, Warszawa, 1989)

5. Kaminski, M. Maj, M., Ubysz A., Chimney cracked reinforced concrete walls as a problem of durability exploitation, SEMC 2013, The 5th International Conference on Structural Engineering, Mechanics and Computation, , 2-4 (Cape Town, South Africa, 2013) 
